\title{
OPEN Genome-wide association study and genomic heritabilities for blood protein levels in Lori-Bakhtiari sheep
}

\author{
P. Zamani $\circledast^{1 凶}$, H. Mohammadi ${ }^{1}$ \& S. Z. Mirhoseini ${ }^{2}$
}

Serum protein levels are related to physiological and pathological status of animals and could be affected by both genetic and environmental factors. This study aimed to evaluate genetic variation of serum protein profile in sheep. Blood samples were randomly collected from 96 Lori-Bakhtiari ewes, a heavy meat-type breed. Total protein, albumin, globulin, $\alpha 1, \alpha 2, \beta$ and $\gamma$ globulins and IgG levels were measured in blood serum. The samples were genotyped using the Illumina OvineSNP50 BeadChip. The studied traits adjusted for age, birth type, birth season and estimate of breeding value for body weight were considered as pseudo-phenotypes in genome-wide association analysis. In the GWAS model, the first five principal components were fitted as covariates to correct the biases due to possible population stratification. The Plink, R and GCTA software were used for genome-wide association analysis, construction of $Q-Q$ and Manhattan plots and estimation of genetic variances, respectively. Noticeable genomic heritabilities \pm SE were estimated for total and $\gamma$ globulins $(0.868 \pm 0.262$ and $0.831 \pm 0.364$, respectively), but other protein fractions had zero or close to zero estimates. Based on the Bonferroni adjusted $p$ values, four QTLs located on $181.7 \mathrm{Mbp}$ of OAR3, 107.7 Mbp of OAR4, 86.3 Mbp of OAR7 and 83.0 Mbp of OAR8 were significantly associated with $\alpha 1$, $\beta, \beta$ and $\gamma$ globulins, respectively. The results showed that the PKP2, IGF2R, SLC22A1 and SLC22A2 genes could be considered as candidate genes for blood serum proteins. The present study showed significant genetic variations of some blood protein fractions.

Animal health and physiological status are main concerns for all livestock producers. Whereby, any physiological and disease problem may endanger livestock production enterprises. Blood serum protein levels could be considered as important indicators for physiological status of animals and a diagnostic aid for many disease types and health disorders ${ }^{1,2}$.

Several functions could be stated for blood serum proteins. For example, albumin involves in binding and transportation of many substances ${ }^{3}$. Globulins, including $\alpha, \beta$ and $\gamma$-globulins, constitute a major category of serum proteins, which include antibodies and involve in hemostatic-fibrinolytic pathways, and transportation of several important molecules, such as Iron, hormones, lipids and vitamins ${ }^{4}$.

It is proven that ovine blood serum protein profile could be affected by several factors, such as age $\mathrm{e}^{2,5-7}, \mathrm{sex}^{5,7}$, body condition score ${ }^{8}$, health condition ${ }^{9}$, season ${ }^{10,11}$, gestation stage $e^{12}$ and birth season ${ }^{6}$. Blood serum protein profile also varies among different ruminant species ${ }^{13}$ and ovine breeds $s^{10,14,15}$.

Low to moderate heritabilities have been estimated for serum total protein (0.20), albumin (0.13), globulins $(0.20)$ and albumin/globulins ratio $(0.21)$ in an Italian Holstein cattle population ${ }^{16}$. There are some reports on genetic diversities of blood serum albumin ${ }^{17-19}$ and albumin/globulins ratio $^{20}$, but genetic variations of other fractions, including, $\alpha, \beta$ and $\gamma$ globulins are mostly unknown.

It has been found that net benefits of selection for disease resistance, would outweigh the opportunity cost of reduced genetic progress in other traits ${ }^{21}$. Detection of QTLs and candidate genes associated with blood serum fractions is a potential method to design an appropriate marker assisted selection program to improve animal health situation and resistance to environmental conditions. A few genome-wide association studies (GWAS) on blood serum protein levels in human, mostly on total protein, albumin and albumin/globulin ratio ${ }^{20,22-24}$. No GWAS report on blood serum protein levels in animals, especially sheep was found in literature. The aim of

${ }^{1}$ Department of Animal Science, Faculty of Agriculture, Bu-Ali Sina University, Hamedan, Iran. ${ }^{2}$ Department of Animal Science, Faculty of Agriculture, University of Guilan, Rasht, Iran. ${ }^{\circledR}$ email: pzamani@basu.ac.ir 
this research was to conduct a genome-wide association study, to identify possible QTLs and candidate genes associated with blood serum protein fractions in sheep.

\section{Methods}

Population and samples. This study was conducted on Lori-Bakhtiari sheep, a heavy meat-type breed of sheep in Zagros area, where is known as the first center of sheep domestication ${ }^{25}$. The studied population was a research flock in Shooli Sheep Breeding Station $\left(32.31362^{\circ} \mathrm{N}, 51.05340^{\circ} \mathrm{E}\right)$, Chaharmahal va Bakhtiari province, Iran. In the studied population, the animals regularly graze on pasture or field residuals during spring to midautumn and in other times are kept indoors and fed by the diets, mainly composed by alfalfa, wheat or barley straw and barley grain. The mating season begins in late August to elongates to late October. More detailed information about climate, diets and managerial conditions in the studied population are provided by Almasi et al. ${ }^{26}$.

A total of 96 ewes were randomly selected among 450 available ewes, in September. The health status of the selected animals was evaluated, based on appetite, body temperature, fecal consistency and parasite tests. Blood samples were taken from jugular vein and collected in both EDTA-free and EDTA-containing tubes.

Blood serum parameters. The samples, collected in EDTA-free tubes, were centrifuged at $2100 \mathrm{~g}$ for $5 \mathrm{~min}$ to separate the serum fraction, which was then used to measure a variety of blood serum protein fractions. The measured serum proteins, were total protein, albumin, total globulins, immunoglobulin $G$ (IgG), and $\alpha 1, \alpha 2, \beta$ and $\gamma$ globulins. Total protein was measured by Biuret method ${ }^{27}$, using a Biochemistry Auto Analyzer (Sinnowa D280, China). Different protein fractions, including, albumin, total globulins and $\alpha 1, \alpha 2, \beta$ and $\gamma$ globulins were separated by electrophoresis of the samples on cellulose acetate strips (Helena Biosciences, UK) in $180 \mathrm{~V}$ for $20 \mathrm{~min}$. Helena electrophoresis interpretation software (Helena Biosciences, UK) was used to read the bands. The IgG levels were measured by the enzyme-linked immunosorbent assay (ELISA) method, using an Awareness Microplate Reader Stat Fax 3200 (Awareness Technology Inc., USA). More detailed information about the methods used to measure blood serum proteins is provided by Mohammadi et al. ${ }^{6}$.

Genotyping and quality control. Genomic DNA was extracted from the EDTA-containing blood samples, using $D N P^{T M}$ Kit (CinnaGen Inc, Iran). The samples were sent to Illumina laboratory and genotyped using the Ovine SNP50 BeadChip (Illumina Inc., CA, USA), which detected a total of 48,054 SNPs in the genome. Quality control process was performed using $\mathrm{R}^{28}$ and Plink 1.90 beta $^{29}$ software, whereby samples with a GenCall (GC) score $<0.6$ and a call rate $<0.99$ and variants with minor allele frequencies (MAF) $<0.05$, genotype call rates $<0.95$ and significant deviation from Hardy-Weinberg equilibrium $\left(p<10^{-6}\right)$ were removed from the analysis.

Statistical analyses. In the first analysis, the phenotypic records of different serum protein fractions were subjected to a general linear model $^{4}$ as follows:

$$
y_{i j k l}=\mu+A_{i}+B_{j}+S_{k}+\beta\left(E B V_{i j k l}\right)+e_{i j k l}
$$

In this model, $y_{i j k l}$ is an observation, $\mu, A_{i}, B_{j}$ and $S_{k}$ are overall mean and effects of age $(2-3,4,5,6$ and +7 years), birth type ( 1 or 2 ) and birth season (winter or spring), respectively, $\beta$ is regression coefficient of the observed parameter on estimate of breeding value for body weight (EBV), as an indicator of genetic potential of body weight and $e_{i j k l}$ is residual effects.

EBVs for body weight were obtained using 15859 test-day body weight records of 4402 individuals, collected during 29 years in the studied population. The EBVs were estimated based on Average-Information algorithm of restricted maximum likelihood (AI-REML), using an animal mixed model fitting animal birth year, birth month, birth type, sex and quadratic regression coefficient of body weight on age, as fixed effects and direct additive genetic and permanent environmental and maternal additive genetic effects as random effects.

The general linear and animal mixed models were analyzed using Proc GLM of SAS ${ }^{30}$ and Wombat software ${ }^{31}$, respectively.

Residuals of the general linear model (1), as adjusted records, were considered as pseudo-phenotypes in genome-wide association analysis. The model used for GWAS, fitted random SNP effects and the first five principal components (PCs) as covariates to account the biases due to possible population stratification. The GWAS was carried out as a single-SNP regression and the SNPs were fitted separately. The genome-wide association p-values were adjusted by Bonferroni adjustment method. The Plink 1.90 beta software ${ }^{29}$ was used for genomewide association analysis. The qqman package of $\mathrm{R}^{32}$ was used to create quantile-quantile (Q-Q) and Manhattan plots. Genomic heritabilities and contributions of the significant SNPs in genetic variation of the studied traits were estimated, based on AI-REML algorithm, using GCTA software ${ }^{33}$.

Gene annotation. Possible candidate genes, located within $50 \mathrm{kbp}$ distances from the detected significant SNPs, based on Bonferonni adjusted p-values, were identified based on SNPchiMp V.3 ovine SNPs genome map $^{34}$, using BioMart tool of Ensembl database (www.ensembl.org). The published QTLs around the significant SNPs were also searched using Animal QTL database (www.animalgenome.org/QTLdb/sheep).

Approval for animal experiments. The experimental protocols were approved by the Biomedical Ethics Committee of Bu-Ali Sina University. All methods were carried out in accordance with relevant guidelines and regulations. The authors also complied with the ARRIVE (Animal Research: Reporting of In Vivo Experiments) guidelines. 

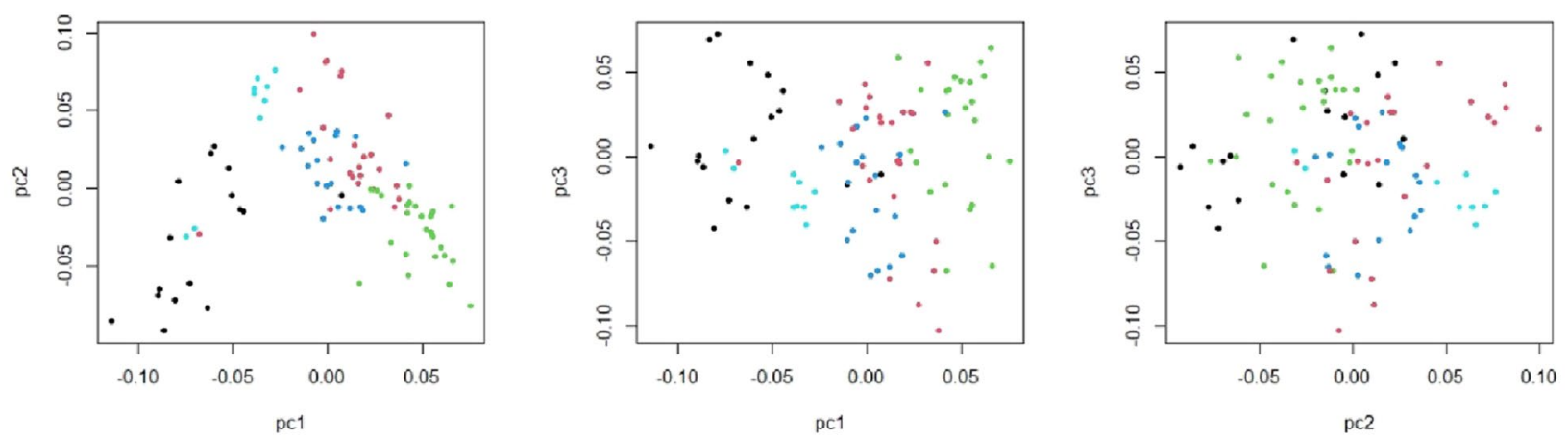

Figure 1. Multi-dimensional scaling (MDS) plots of the genotyping data, based on the first three PCs. Each dot is an animal and different dot colours represent clustering solutions.

\section{Results \\ Descriptive statistics. Averages \pm standard deviations of total protein, albumin, globulins, $\alpha 1$ globulin, $\alpha 2$ globulin, $\beta$ globulin, $\gamma$ globulin and IgG, were $5.82 \pm 0.97,2.35 \pm 0.51,3.47 \pm 0.82,0.06 \pm 0.05,0.42 \pm 0.17$, $0.15 \pm 0.14,2.82 \pm 0.76$ and $1.56 \pm 0.41 \mathrm{~g} / \mathrm{dL}$, respectively. Average \pm standard deviation of albumin/globulin ratio was $0.69 \pm 0.22$.}

Quality control. In quality control, two samples had call rates lower than 0.99 (actually $<0.7$ ) and thus were removed from the analysis. A total of 4931 SNPs with MAF $<0.05,1283$ SNPs with genotype call rates $<0.95$ and one SNP with significant Hard-Weinberg disequilibrium were also withdrawn from the analysis. As the result of quality control, a total of 94 samples and 41839 SNPs were used for the final analysis.

Estimates of genomic heritability. Estimates of genomic heritabilities \pm SE were $0.000 \pm 0.296$ for total protein, $0.000 \pm 0.299$ for albumin, $0.868 \pm 0.262$ for globulins, $0.227 \pm 0.313$ for albumin/globulin ratio, $0.264 \pm 0.337$ for $\alpha 1$ globulin, $0.000 \pm 0.288$ for $\alpha 2$ globulin, $0.000 \pm 0.306$ for $\beta$ globulin, $0.831 \pm 0.364$ for $\gamma$ globulin and $0.000 \pm 0.266$ for IgG.

Genome-wide association analysis. Multi-dimensional scaling (MDS) plots of the genotyping data, based on the first three PCs did not show any obvious classification of the sampled animals. However, a slight stratification was observed based on the first two PCs. Whereby a few animals, as the first cluster (black dots) had a slight distance from the others (Fig. 1). This slight stratification is probably due to interfamily differences and import of rams from other populations.

Estimates of genomic inflation factor $(\lambda)$ in the association analysis for total protein, albumin, globulins, albumin/globulins ratio, $\alpha 1$ globulin, $\alpha 2$ globulin, $\beta$ globulin, $\gamma$ globulin and IgG were 1.01, 1.00, 1.02, 1.00, 1.00, $1.00,1.03,1.07$ and 1.00 , respectively. Q-Q plots of GWAS - $\log 10$ ( $p$ values) for the studied traits are presented in the Fig. 2.

In genome-wide association analysis, a total of six SNPs had genome-wide $p$ values $<10^{-5}$. However, based on Bonferroni adjusted $p$ values, four SNPs, including one SNP on chromosome 3 (rs411530530), two SNPs on chromosomes 7 (rs429230884) and 4 (rs401001039), and one SNP on chromosome 8 (rs427910139) had significant associations $(p<0.05)$ with $\alpha 1, \beta$ and $\gamma$ globulins, respectively (Table 1$)$. Other SNPs did not show any significant association with the studied traits. Manhattan plots of GWAS - $\log 10$ ( $p$ values) for the studied traits are presented in the Fig. 3.

Genes and QTLs annotation. Based on BioMart tool of Ensembl database (www.ensembl.org), a total of five genes were found within $50 \mathrm{kbp}$ distances from the significant SNPs. The genes found were plakophilin 2 (PKP2) gene on chromosome 3, ENSOARG00000017510 on chromosome 7, and three genes, including insulin like growth factor 2 receptor (IGF2R), solute carrier family 22 members 1 and 2 (SLC22A1 and SLC22A2, respectively) on chromosome 8 . No gene was found within $50 \mathrm{kbp}$ intervals from the significant SNP on chromosome 4 (Table 2). The genes surrounding the significant SNPs on chromosomes 3, 4, 7 and 8 are illustrated in Fig. 4. Based on the Animal QTL database (Animal QTLdb), no QTL associated with the studied blood serum proteins was found around the significant SNPs. However, some QTLs associated with immunoglobins A (IgA), $\mathrm{E}(\mathrm{IgE})$ and $\mathrm{G}(\mathrm{IgG})$ were found in the Animal QTL database.

\section{Discussion}

Total protein and globulins, albumin, albumin to globulins ratio and $\gamma$ globulin averages were in the range, reported for different populations, such as Merino sheep ${ }^{13,35}$, Karakul and Tzurcana ewes ${ }^{10,13}$, Balami ewes ${ }^{14}$, Lori-Bakhtiari and Mehraban sheep ${ }^{36}$ and Santa Inês ewes ${ }^{37}$. However, averages of $\alpha 1, \alpha 2$ and $\beta$ globulins levels were to some extent lower than those reported in literature ${ }^{9,13,36}$. The observed differences are probably due to different environmental, physiological, health, age and genetic conditions of the studied populations. For example, it has been found that sick animals may have higher levels of $\alpha$ and $\beta$ globulins ${ }^{9}$. 


\section{A: Total protein}

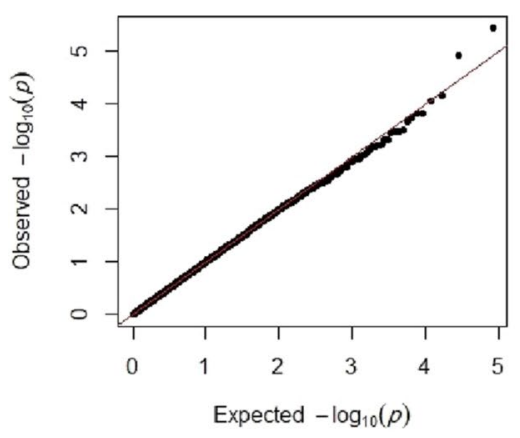

D: A/G ratio

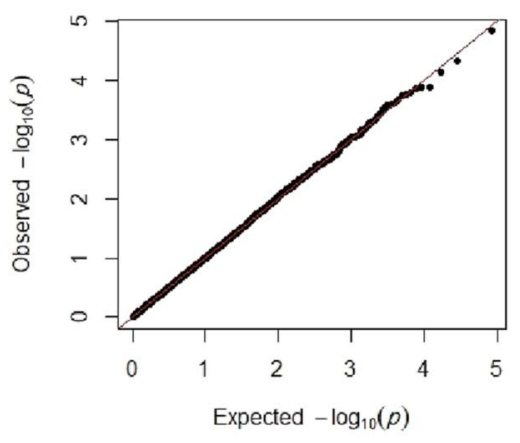

G: $\beta$ globulin

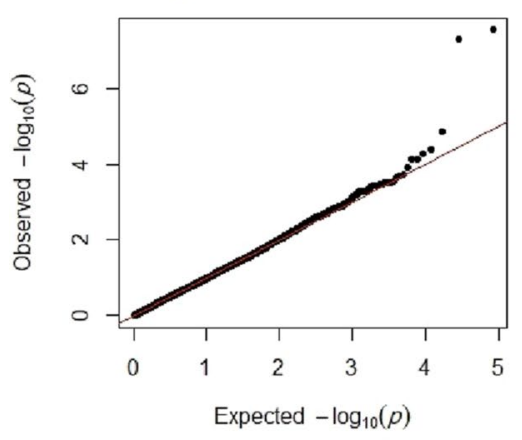

B: Albumin

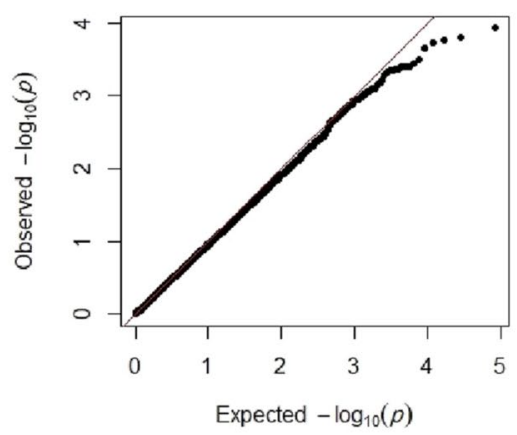

E: $\alpha 1$ globulin

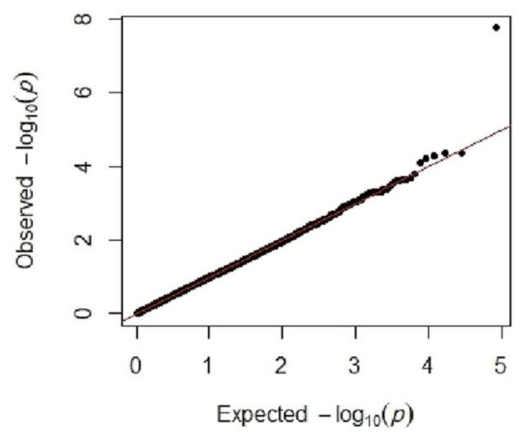

$\mathrm{H}: \boldsymbol{v}$ globulin

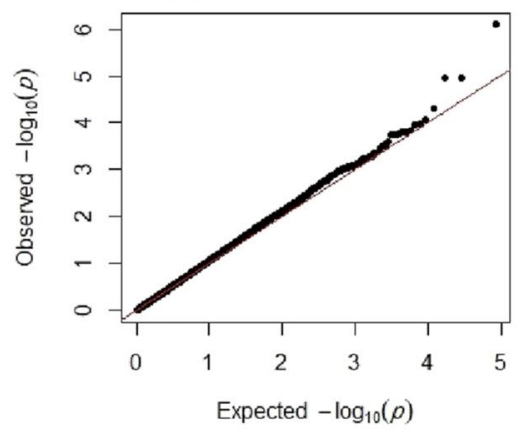

C: Globulins

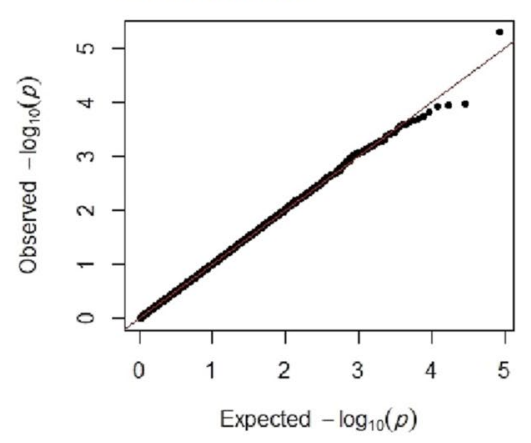

F: $\alpha 2$ globulin

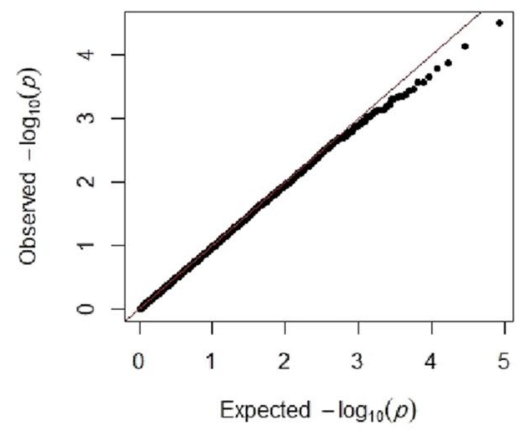

I: IgG

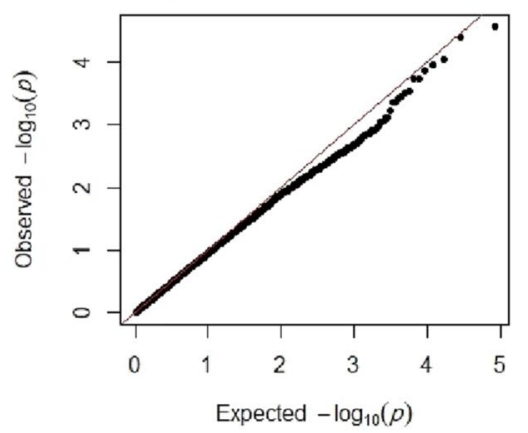

Figure 2. Quantile-quantile (Q-Q) plots for total protein (A), albumin (B), globulins (C), albumin/globulin ratio (D), a1 globulin (E), a 2 globulin $(\mathbf{F}), \beta$ globulin $(\mathbf{G}), \gamma$ globulin $(\mathbf{H})$ and IgG (I). The dots are GWAS

$-\log 10$ ( $p$ values) and the line represents the expected values for no association.

\begin{tabular}{|l|l|l|l|l|l|l|}
\hline Protein fraction & SNP & Chr. & FS Alleles & Location $($ bp) & $\begin{array}{l}\text { G } \\
\boldsymbol{p} \text { value }\end{array}$ & $\begin{array}{l}\text { B } \\
\boldsymbol{p} \text { value }\end{array}$ \\
\hline$\alpha 1$ & $\mathrm{r} 411530530$ & 3 & $\mathrm{~T} / \mathrm{C}$ & 181680527 & $1.761 \mathrm{e}-08$ & 0.0007 \\
\hline$\beta$ & $\mathrm{r} 429230884$ & 7 & $\mathrm{~A} / \mathrm{G}$ & 86283700 & $2.858 \mathrm{e}-08$ & 0.0012 \\
\hline$\beta$ & $\mathrm{r} 401001039$ & 4 & $\mathrm{~A} / \mathrm{G}$ & 107694115 & $5.112 \mathrm{e}-08$ & 0.0021 \\
\hline$\gamma$ & $\mathrm{r} 427910139$ & 8 & $\mathrm{~A} / \mathrm{G}$ & 82987574 & $8.105 \mathrm{e}-07$ & 0.0339 \\
\hline TP & $\mathrm{r} 424180409$ & 15 & $\mathrm{~A} / \mathrm{G}$ & 14720397 & $3.671 \mathrm{e}-06$ & 0.1536 \\
\hline Glo & $\mathrm{r} 427910139$ & 8 & $\mathrm{~A} / \mathrm{G}$ & 82987574 & $5.125 \mathrm{e}-06$ & 0.2144 \\
\hline
\end{tabular}

Table 1. Significant SNPs detected in genome-wide association analysis for the studied traits. $\alpha 1, \beta, \gamma, \mathrm{TP}$ and Glo stand for $\alpha 1, \beta$ and $\gamma$ globulins, total protein and globulins, respectively; Chr. is chromosome number; FS alleles are forward strand alleles; $\mathrm{G} p$ value and $\mathrm{B} p$ value are genome-wide and Bonferroni-adjusted $p$ values, respectively; GVE is genetic variance explained by the SNP. 


\section{A: Total protein}

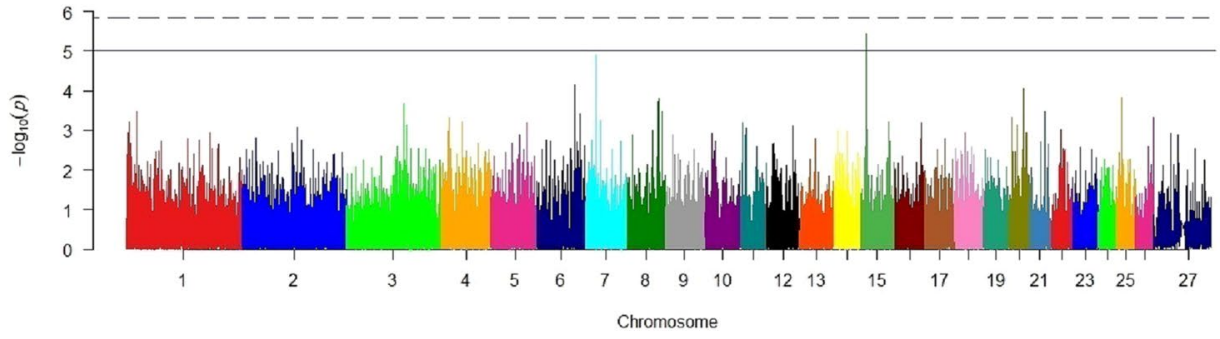

B: Albumin

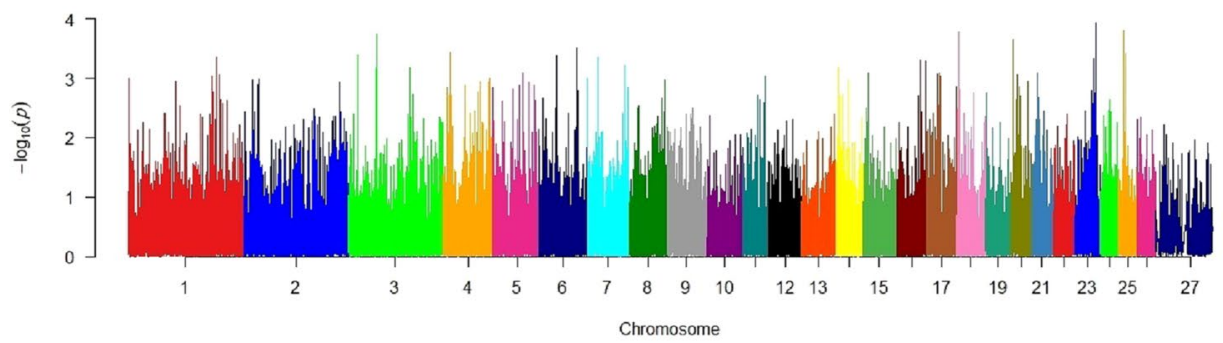

\section{C: Globulins}

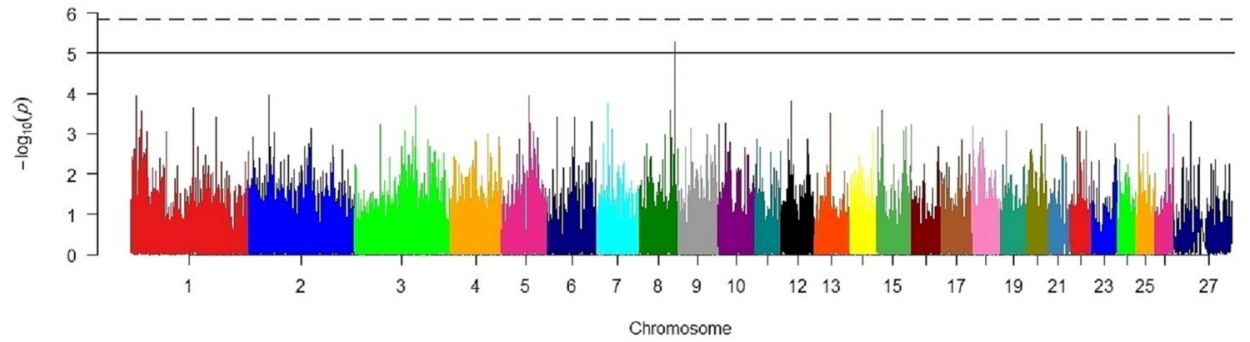

\section{D: A/G ratio}
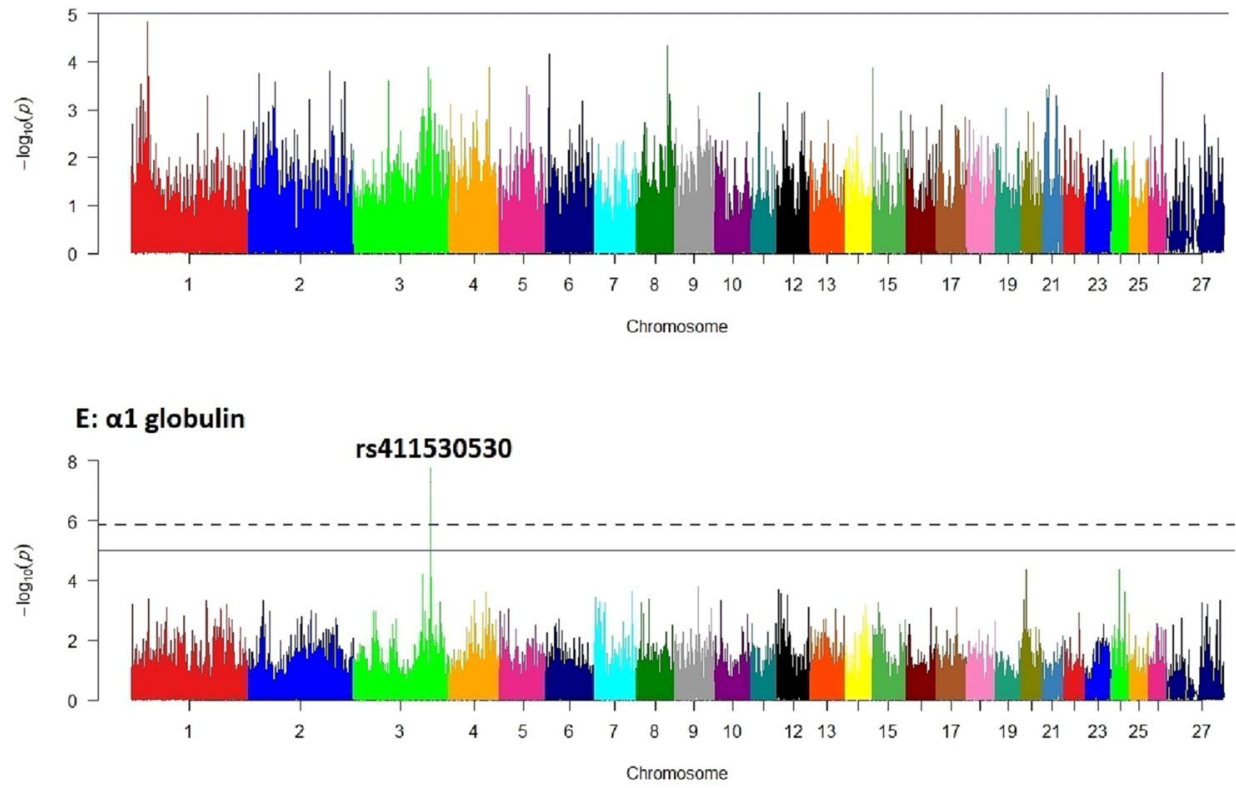

Figure 3. Manhattan plots of genome-wide $-\log 10$ ( $p$ values) for the studied traits. Solid and dashed horizontal lines show genome-wide $p$ values of $10^{-5}$ and $1.19 \times 10^{-6}$ (Bonferroni adjusted $p$ value $=0.05$ ), respectively; A: total protein, B: albumin, C: globulins, D: albumin/globulin ratio, E: $\alpha 1$ globulin, F: $\alpha 2$ globulin, G: $\beta$ globulin, $\mathrm{H}: \gamma$ globulin and I: IgG. 


\section{F: $\alpha 2$ globulin}

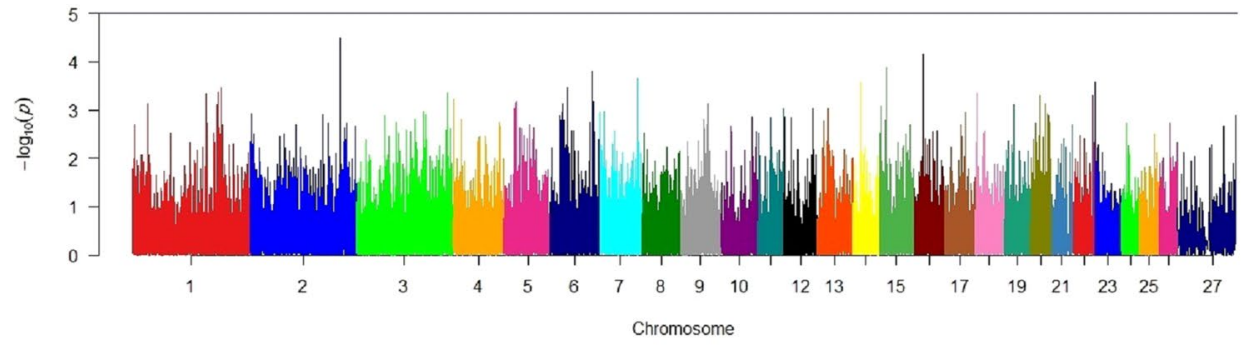

\section{G: $\beta$ globulin}

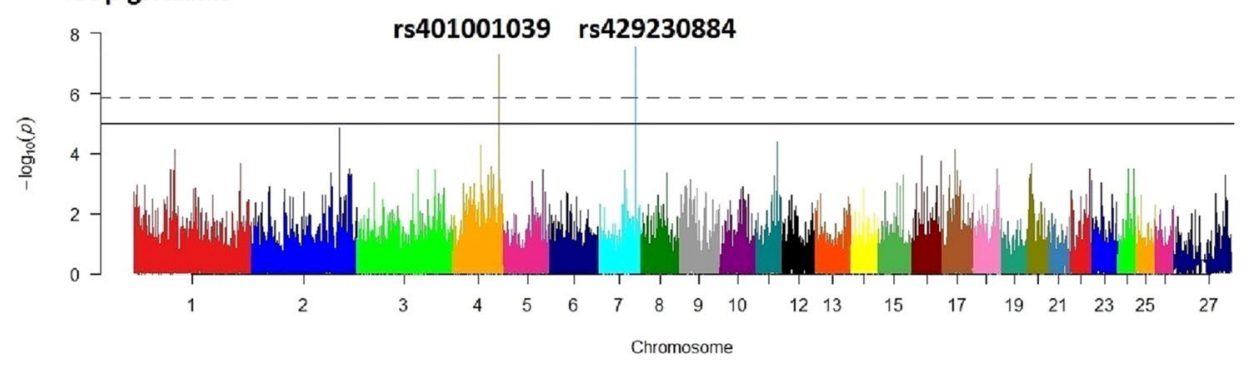

\section{H: $\boldsymbol{y}$ globulin}
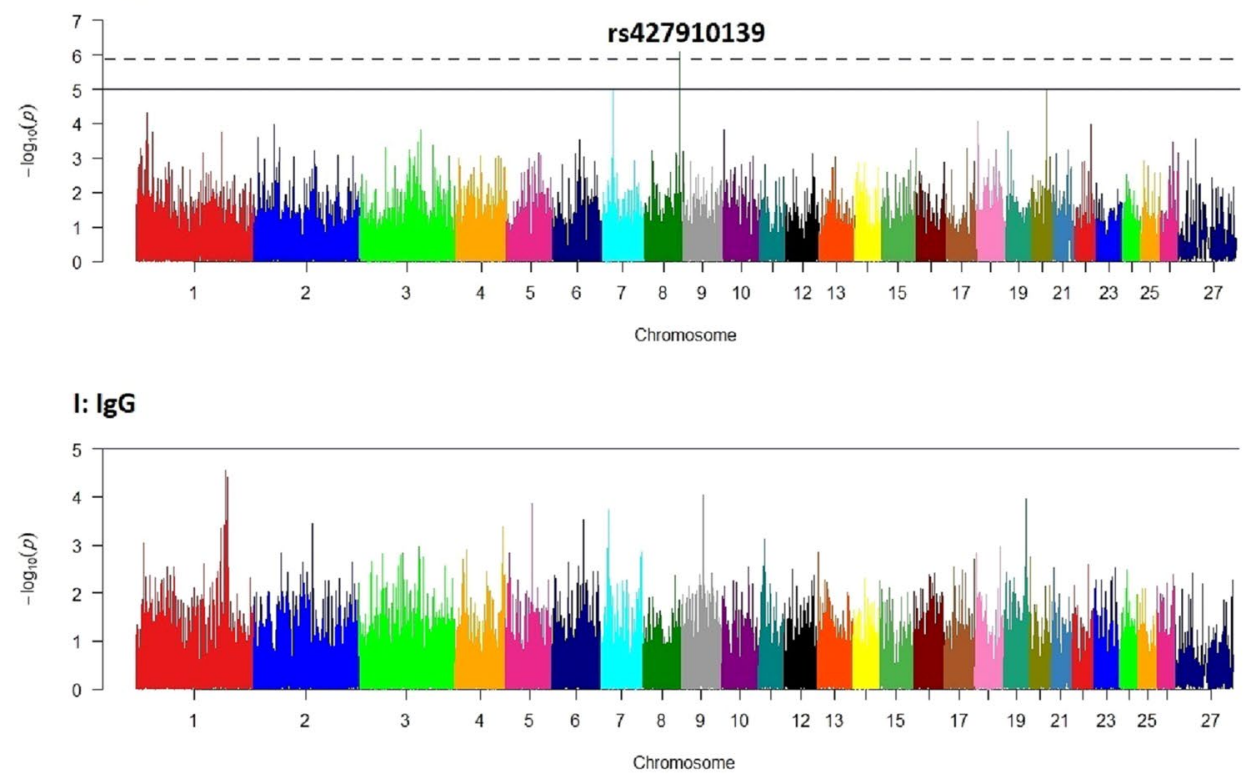

Figure 3. (continued)

\begin{tabular}{|l|l|l|l|l|l|l|l|}
\hline SNP & Chr & Location (bp) & Gene & Strand & Gene start (bp) & Gene end (bp) & Distance \\
\hline rs411530530 & 3 & 181680527 & PKP2 & F & 181710282 & 181800739 & -29755 \\
\hline rs401001039 & 4 & 107694115 & - & F & - & - & - \\
\hline rs429230884 & 7 & 86283700 & ENSOARG00000017510 & F & 86330934 & 86331638 & -47234 \\
\hline \multirow{3}{*}{ rs427910139 } & \multirow{2}{*}{8} & \multirow{2}{*}{82987574} & IGF2R & F & 82874886 & 82959397 & 28177 \\
\cline { 4 - 8 } & & & SLC22A1 & F & 82967383 & 83002611 & Within \\
\cline { 3 - 7 } & & SLC22A2 & R & 83028720 & 83060568 & -41146 \\
\hline
\end{tabular}

Table 2. The genes found in $50 \mathrm{kbp}$ distances from the detected significant SNPs in GWAS, based on BioMart tool of Ensembl database (www.ensembl.org). PKP2: Plakophilin 2; IGF2R: Insulin like growth factor 2 receptor; SLC22A1: Solute carrier family 22 member 1; SLC22A2: Solute carrier family 22 member 2; F and R: forward and reverse strands, respectively; Negative and positive distances indicate the SNPs before and after the genes, respectively. 


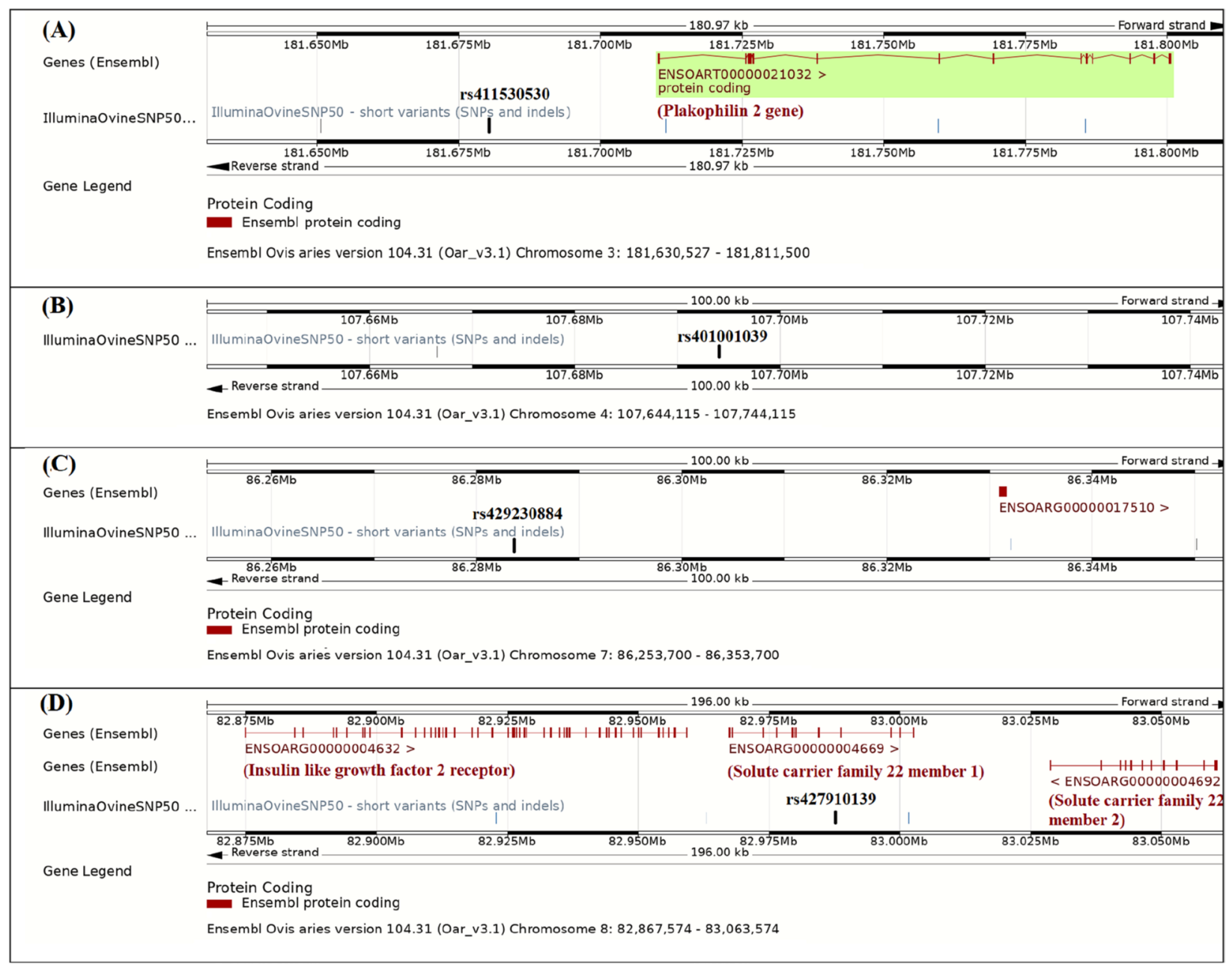

Figure 4. The genes found within $50 \mathrm{kbp}$ distances from the significant SNPs on chromosomes 3 (A), 4 (B), 7 (C) and 8 (D), based on BioMart tool of Ensembl (www.ensembl.org).

In the present study, moderate to high genomic heritabilities were estimated for total globulins (0.868), albu$\mathrm{min} /$ globulin ratio $(0.227), \alpha 1$ globulin $(0.264)$ and $\gamma$ globulin $(0.831)$, which indicates considerable genetic effects on these protein fractions and probably their potential use as biomarkers for genetic selection. Other fractions, with negligible heritabilities, including total protein, albumin, $\alpha 2$ globulin, $\beta$ globulin and IgG are likely proper guides to animal management ${ }^{38}$. The present study is probably the first published attempt to estimate genomic heritabilities of the blood protein levels. However, based on high standard errors of the heritability estimates, which was due to limited number of the sampled animals, more studies are still needed to clarify exact genetic bases of blood serum protein variations.

The significant SNPs detected on chromosomes 3, 4, 7 and 8 (Table 1) were not located near to the reported QTLs associated to blood serum proteins. However, a total of 32 QTLs for IgA on chromosomes 1, 2, 3, 4, 6, 9, 10,11, 12, 13, 15, 16, 17, 20, 21, 22 and 23, one QTL for IgE on chromosome 23 and four QTLs for IgG on chromosomes 5, 9 and 23 were found in Animal QTL database (www.animalgenome.org/QTLdb/sheep). Based on Animal QTLdb, the reported QTLs for IgA on OAR3 and OAR4 are located on 138.6-150.3 Mbp of OAR3 ${ }^{39}$, 155.9-156.0 Mbp of OAR3 ${ }^{40}, 200.2$ and 209.7 Mbp of OAR3 ${ }^{41}, 54.0-58.0$ of OAR4 ${ }^{42}$, and 76.4 and 82.5 Mbp of $\mathrm{OAR}^{41}$, which are different from the detected SNPs on 181.7 Mbp of OAR3 and 107.7 Mbp of OAR4 in the present study (Table 1). No QTL was found for serum total protein, albumin, globulins, $\alpha 1, \alpha 2, \beta$ and $\gamma$ globulins in Animal QTLdb for sheep. However, despite QTLs, a total of five genes, including PKP2, ENSOARG00000017510, $I G F 2 R, S L C 22 A 1$ and SLC22A2 were found in $50 \mathrm{kbp}$ distances from the significant SNPs on chromosomes 3, 7 and 8 (Table 2).

A few genome-wide association studies have been conducted on blood serum proteins. A GWAS on Korean population revealed six loci, including TNFRSF13B, FADS1, GALNT2, IRF4, HLA-DBP1 and SLC31A1, associated with albumin/globulin ratio ${ }^{20}$. In a GWAS on Japanese human population, based on two significant SNPs for total protein and one significant SNP for albumin, five genes, including TNFRSF13B, RPL13A, RPS11, FCGRT and RCN3 and one gene, GCKR were suggested as candidate genes for total protein and albumin levels, respectively ${ }^{22}$. Associations of the TNFRSF13B and GCKR genes with total protein and albumin levels were also confirmed in another GWAS on Japanese people ${ }^{24}$. In a GWAS meta-analysis on east-Asian human population, one SNP, located within the RRPS11 gene, was significantly associated with blood plasma albumin level ${ }^{23}$. Almost 
different candidate genes for blood protein fractions were found in the present and previous GWASs, which is probably due to population-specific associations $\mathrm{s}^{22}$ and different genetic architectures of the studied populations and individuals ${ }^{43}$.

The plakophilin 2 gene (PKP2), located on OAR3, encodes the plakophilin 2 protein, which is mainly found in myocardium cells the heart wall. This protein is a found in desmosome structures, a component of intercellular adhesive junction ${ }^{44,45}$. The compromised junctional integrity probably contributes to disease pathophysiology ${ }^{46}$. Although PKP2 serves as a critical scaffold for protein kinase $\mathrm{Ca}(\mathrm{PKC} \alpha)$. Thus, more global functions in cellular homeostasis are expected for PKP2. It has been found that PKP2 knockdown would result in increased PKC substrate phosphorylation, and this association is probably the reason for pathogenesis of congenital defects due to PKP2 deficiency ${ }^{46}$. In several studies, the PKP2 gene was associated with canine atopic dermatitis, a chronic inflammatory skin disease $\mathrm{e}^{47,48}$. It has been found that the $P K P 2$ impacts the $\beta$-catenin activity, a main participant in canonical Wnt signaling and associates with SOX2 and SOX9 expressions, as Wnt target genes, which suggests a signaling role of plakophilin 2 by regulation of Wnt signaling pathway ${ }^{49}$. On the other hand, it is demonstrated that the Wnt signaling is essential in pathogenesis of some diseases ${ }^{50}$. Thus, the PKP2 gene could be considered as a candidate gene for blood serum proteins.

The ENSOARG00000017510 gene, is located on $86.3 \mathrm{Mbp}$ of OAR7, in a $47.2 \mathrm{kbp}$ distance from the SNP rs429230884 (Table 2). Based on the Ensembl database (www.ensembl.org), the ENSOARG00000017510 is a protein-coding gene, which encodes an integral component of membrane. No evidence for phenotypic association of this gene with diseases or other traits was found in literature. It seems that more studies are needed to understand the molecular, cellular and biological functions of this gene.

The insulin like growth factor 2 receptor (IGF2R) is locates on OAR8 and encodes a highly conserved transmembrane glycoprotein receptor which regulates the insulin-like growth factor 2 (IGF2) level and this function is necessary for embryonic development in mammals ${ }^{51}$. However, there are some evidences for IGF2R functions in immunity such as regulation of HIV infection and chemokine expression ${ }^{52}$, overexpression of IGF2R in osteosarcoma cells $\mathrm{s}^{53}$ and increase of regulatory $\mathrm{T}$ cell functions in reducing of other effector $\mathrm{T}$ cells activities and suppression of food allergic effects on intestinal inflammation ${ }^{54}$. Moreover, it has been found that some viral infections are associated with IGF system ${ }^{52}$. Therefore, the IGF2R is probably a candidate gene for blood serum proteins and immune system activity.

The significant SNP on OAR8 (rs427910139) is located within and in $41 \mathrm{kbp}$ distance from the solute carrier family 22 members 1 (SLC22A1) and 2 (SLC22A2), respectively (Fig. 4, part D). The SLC22A1 and SLC22A2 encode organic cation transporters, with crucial roles in elimination of endogenous organic cations, drugs and toxin $^{55}$. Associations of SLC22 members 1-3 with drug disposition, response and generally pharmacodynamics are well known ${ }^{56,57}$. There are several evidences for associations of SLC22A1 and SLC22A2 with diseases. For example, the SLC22A2 is associated with hypertension ${ }^{58}$ and $S L C 22 A 1$ and $S L C 22 A 2$, both contribute in disposition pathways for fluoroquinolone antimicrobials ${ }^{59}$. In a GWAS on Korean human population, another member of the solute carrier families (SLC31A1) was significantly associated with blood serum albumin/globulin ratio ${ }^{20}$. Therefore, both $S L C 22 A 1$ and $S L C 22 A 2$ could be considered as candidate genes for blood serum protein profile and probably resistance to diseases.

\section{Conclusion}

The QTLs on 181.7 Mbp of OAR3, 107.7 Mbp of OAR4, 86.3 Mbp of OAR7 and 83.0 Mbp of OAR8 in the present study are probably the first QTLs reported for $\alpha 1, \beta$ and $\gamma$ globulins. Moreover, the PKP2, IGF2R, SLC22A1 and $S L C 22 A 2$ genes could be considered as candidate genes for blood serum proteins. Moderate to high genomic heritabilities were estimated for total globulins (0.868), albumin/globulin ratio (0.227), al globulin (0.264) and $\gamma$ globulin (0.831). This study showed considerable genetic variation in blood serum protein profile, especially total and gamma globulins. This study is probably the first GWAS on blood serum protein profile in animals. However, more studies with larger sample sizes and use of high-density SNP chips would probably result in detection of more genomic regions associated with blood serum protein profile in sheep.

Received: 13 September 2021; Accepted: 1 December 2021

Published online: 09 December 2021

\section{References}

1. Tothova, C., Mihajlovičová, X. \& Nagy, O. The electrophoretic pattern of serum proteins in dairy cows with inflammatory diseases. Acta Vet. 67, 178-190 (2017)

2. Tothova, C., Nagy, O. \& Kovac, G. Serum proteins and their diagnostic utility in veterinary medicine: a review. Vet. Med. 61, 475-496 (2016).

3. Merlot, A. M., Kalinowski, D. S. \& Richardson, D. R. Unraveling the mysteries of serum albumin-More than just a serum protein. Front. Physiol. 5, 299 (2014).

4. Alberghina, D. et al. Analysis of serum proteins in clinically healthy goats (Capra hircus) using agarose gel electrophoresis. Vet. Clin. Pathol. 39, 317-321 (2010).

5. da Cruz, R.E.S. et al. Effects of age and sex on blood biochemistry of Dorper lambs. Semina: Cienc. Agrar. 38, 3085-3093 (2017).

6. Mohammadi, H., Zamani, P. \& Mirhoseini, S. Z. Serum protein profile of Lori-Bakhtiari ewes in relation to age, body weight, birth type and birth season. Iran. J. Appl. Anim. Sci. (2022).

7. Rahman, M. K. et al. Determination of hematological and serum biochemical reference values for indigenous sheep (Ovies aries) in Dhaka and Chittagong districts of Bangladesh. Vet. World. 11, 1089-1093 (2018).

8. Carlos, M. M. L. et al. Blood parameters in the Morada Nova sheep: Influence of age, sex and body condition score. J. Anim. Plant Sci. 25, 950-955 (2015).

9. Esmaeilnejad, B., Tavassoli, M., Asri-Rezaei, S., Dalir-Naghadeh, B. \& Pourseyed, S. H. Evaluation of serum total protein concentration and protein fractions in sheep naturally infected with Babesia ovis. Comp. Clin. Pathol. 23, 151-155 (2014). 
10. Murariu, O. C., Lazăr, R., Murariu, F., Paul, C. \& Boișteanu, P. C. Variation of biochemical parameters of ovine blood according to genotype and sex after the stalling period. Bull. Univ. Agric. Sci. Vet. Med. Cluj-Napoca. Anim. Sci. Biotechnol. 71, 73-75 (2014).

11. Piccione, G. et al. Seasonal variations of the serum proteins in sheep and goats. Arch. Anim. Breed. 54, 399-405 (2011).

12. Batavani, R. A., Ansari, M. H. \& Asri, S. Concentrations of serum total protein and protein fractions during diestrus and pregnancy in Makuii ewes. Comp. Clin. Pathol. 15, 227-230 (2006).

13. Nagy, O., Tóthová, C., Nagyová, V. \& Kováč, G. Comparison of serum protein electrophoretic pattern in cows and small ruminants. Acta Vet. Brno. 84, 187-195 (2015).

14. Njidda, A. A., Shuai'bu, A. A. \& Isidahomen, C. E. Haematological and serum biochemical indices of sheep in semi-arid environment of northern Nigeria. Glob. J. Sci. Front. Res. D: Agric. Vet. 14(2), 49-56 (2014).

15. Nigussie, H. et al. Phenotypic variation and protein polymorphism of indigenous sheep breeds in eastern Ethiopia. Livest. Res. Rural Dev. 28, 139 (2016).

16. Cecchinato, A. et al. Genetic variation in serum protein pattern and blood $\beta$-hydroxybutyrate and their relationships with udder health traits, protein profile, and cheese-making properties in Holstein cows. J. Dairy Sci. 101, 11108-11119 (2018).

17. Erhardt, G. \& Simianer, H. Linkage between the loci for serum albumin and vitamin D binding protein (GC) in sheep. Anim. Genet. 24, 301-303 (1993).

18. Franceschini, N. et al. Discovery and fine mapping of serum protein loci through transethnic meta-analysis. Am. J. Hum. Genet. 91, 744-753 (2012).

19. Morera, L., Llanes, D., Barbancho, M. \& Rodero, A. Genetic polymorphism in Spanish Merino sheep. Anim. Blood Groups Biochem. Genet. 14, 77-82 (1983).

20. Hong, K. W. et al. Genome-wide association study of serum albumin: Globulin ratio in Korean populations. J. Hum. Genet. 58, 174-177 (2013).

21. Bishop, S. C., Axford, R. F. E., Nicholas, F. W. \& Owen, J. B. Introduction, in Breeding for Disease Resistance, 3rd edn. 3-14 (CAB International, UK, 2010).

22. Kamatani, Y. et al. Genome-wide association study of hematological and biochemical traits in a Japanese population. Nat. Genet. 42, 210-215 (2010).

23. Kim, Y. J. et al. Large-scale genome-wide association studies in East Asians identify new genetic loci influencing metabolic traits. Nat. Genet. 43, 990-995 (2011).

24. Osman, W. et al. Association of common variants in TNFRSF13B, TNFSF13, and ANXA3 with serum levels of non-albumin protein and immunoglobulin isotypes in Japanese. PLoS One. 7, e32683 (2012).

25. Zeder, M. A. Animal domestication in the Zagros: A review of past and current research. Paléorient. 25(2), 11-26 (1999).

26. Almasi, M., Zamani, P., Mirhoseini, S. Z. \& Moradi, M. H. Genome-wide association study for weaning traits in a meat type sheep. Ann. Anim. Sci. 20, 811-824 (2020).

27. Burtis, C. A. \& Bruns, D. E. Tietz fundamentals of clinical chemistry and molecular diagnostics 7 th edn. (Elsevier, 2014).

28. R Core Team. R: A language and environment for statistical computing, R Foundation for Statistical Computing. Citeseer, Vienna, Austria (2013).

29. Chang, C. C. et al. Second-generation PLINK: Rising to the challenge of larger and richer datasets. GigaScience 4, 1-16 (2015).

30. SAS Institute. Users Guide, Version 9.4: Statistics. SAS Institute, Cary, NC, USA. Iran. J. Anim. Sci. 12(1), (2022).

31. Meyer, K. WOMBAT-A tool for mixed model analyses in quantitative genetics by restricted maximum likelihood (REML). J. Zhejiang Univ. Sci. B. 8, 815-821 (2007).

32. Turner, S. D. qqman: An R package for visualizing GWAS results using QQ and manhattan plots. BioRxiv 3, 5165 (2014).

33. Yang, J., Lee, S. H., Goddard, M. E. \& Visscher, P. M. GCTA: A tool for genome-wide complex trait analysis. Am. J. Hum. Genet. 88, 76-82 (2011).

34. Nicolazzi, E. L. et al. SNPchiMp vol 3: Integrating and standardizing single nucleotide polymorphism data for livestock species. BMC Genomics 16, 283 (2015).

35. Lepherd, M. L., Canfield, P. J., Hunt, G. B. \& Bosward, K. L. Haematological, biochemical and selected acute phase protein reference intervals for weaned female Merino lambs. Aust. Vet. J. 87, 5-11 (2009).

36. Zamani, P., Salehian Dehkordi, H., Doosti, A. \& Abdolmohammadi, A. Ovine DRB1 polymorphism and its associations with body weight, milk contents and immunological parameters. Ann. Anim. Sci. 16, 425-438 (2016).

37. Sabes, A. F., Girardi, A. M., Fagliari, J. J., de Oliveira, J. A. \& Marques, L. C. Serum proteinogram in sheep with acute ruminal lactic acidosis. Int. J. Vet. Sci. Med. 5, 35-40 (2017).

38. Li, J. et al. Genomic heritability and genome-wide association studies of plasma metabolites in crossbred beef cattle. Front. Genet. $11,538600(2020)$.

39. Davies, G. et al. Quantitative trait loci associated with parasitic infection in Scottish blackface sheep. Heredity 96, 252-258 (2006).

40. Coltman, D. W., Wilson, K., Pilkington, J. G., Stear, M. J. \& Pemberton, J. M. A microsatellite polymorphism in the gamma interferon gene is associated with resistance to gastrointestinal nematodes in a naturally-parasitized population of Soay sheep. Parasitology. 122, 571-582 (2001).

41. Riggio, V., Matika, O., Pong-Wong, R., Stear, M. J. \& Bishop, S. C. Genome-wide association and regional heritability mapping to identify loci underlying variation in nematode resistance and body weight in Scottish Blackface lambs. Heredity. 110, 420-429 (2013).

42. Atlija, M., Arranz, J. J., Martinez-Valladares, M. \& Gutiérrez-Gilet, B. Detection and replication of QTL underlying resistance to gastrointestinal nematodes in adult sheep using the ovine 50K SNP array. Genet. Sel. Evol. 48, 4 (2016).

43. Zhong, W. et al. Whole-genome sequence association analysis of blood proteins in a longitudinal wellness cohort. Genome Med. 12, $53(2020)$.

44. Cerrone, M. et al. Plakophilin-2 is required for transcription of genes that control calcium cycling and cardiac rhythm. Nat. Commun. 8, 106 (2017).

45. Godsel, L. M. et al. Plakophilin 2 couples actomyosin remodeling to desmosomal plaque assembly via RhoA. Mol. Biol. Cell. 21, 2844-2859 (2010).

46. Bass-Zubek, A. E. et al. Plakophilin 2: A critical scaffold for PKC alpha that regulates intercellular junction assembly. J. Cell Biol. 181, 605-613 (2008).

47. Tengvall, K. et al. Multiple regulatory variants located in cell type-specific enhancers within the PKP2 locus form major risk and protective haplotypes for canine atopic dermatitis in German shepherd dogs. BMC Genet. 17, 97 (2016).

48. Wood, S. H. et al. Gene expression in canine atopic dermatitis and correlation with clinical severity scores. J. Dermatol. Sci. 55, 27-33 (2009).

49. Khudiakov, A. A., Kostina, D. A., Kostareva, A. A., Tomilin, A. N. \& Malashicheva, A. B. The effect of plakophilin-2 gene mutations on the activity of canonical WNT signaling. Cell Tiss. Biol. 10, 106-113 (2016).

50. Prunier, C., Hocevar, B. A. \& Howe, P. H. Wnt signaling: physiology and pathology. Growth Factors. 22, 141-150 (2004).

51. Nolan, C. M. Igf2r Locus. In Brenner's Encyclopedia of Genetics (Second Edition) (eds Maloy, S. \& Hughes, K.) 15-17 (Academic Press, 2013).

52. Suh, H. S. et al. Insulin-like growth factor 2 receptor is an IFN $\gamma$-inducible microglial protein that facilitates intracellular HIV replication: Implications for HIV-induced neurocognitive disorders. Am. J. Pathol. 177, 2446-2458 (2010).

53. Hassan, S. E. et al. Cell surface receptor expression patterns in osteosarcoma. Cancer. 118, 740-749 (2011). 
54. Yang, G. et al. Insulin-like growth factor 2 enhances regulatory T-cell functions and suppresses food allergy in an experimental model. J. Allergy Clin. Immunol. 133, 1702-1708.e5 (2014).

55. Nigam, S. K. The SLC22 transporter family: A paradigm for the impact of drug transporters on metabolic pathways, signaling, and disease. Annu. Rev. Pharmacol. Toxicol. 58, 663-687 (2018).

56. Cheong, H. S. et al. Screening of genetic variations of SLC15A2, SLC22A1, SLC22A2 and SLC22A6 genes. J. Hum. Genet. 56, 666-670 (2011).

57. Wagner, D. J., Hu, T. \& Wang, J. Polyspecific organic cation transporters and their impact on drug intracellular levels and pharmacodynamics. Pharmacol. Res. 111, 237-246 (2016).

58. Lazar, A. et al. Lower prevalence of the OCT2 Ser270 allele in patients with essential hypertension. Clin. Exp. Hypertens. 28, 645-653 (2006).

59. Mulgaonkar, A., Venitz, J., Gründemann, D. \& Sweet, D. H. Human organic cation transporters 1 (SLC22A1), 2 (SLC22A2), and 3 (SLC22A3) as disposition pathways for fluoroquinolone antimicrobials. Antimicrob. Agents Chemother. 57, 2705-2711 (2013).

\section{Acknowledgements}

The authors are thankful to Dr. R. Abdoli, Dr. M. Almasi and Dr. H. Salehian for their cooperation and advises.

\section{Author contributions}

The data were collected by P.Z. and S.Z.M. and analyzed by P.Z. and H.M. All authors contributed in writing and editing the paper.

\section{Competing interests}

The authors declare no competing interests.

\section{Additional information}

Correspondence and requests for materials should be addressed to P.Z.

Reprints and permissions information is available at www.nature.com/reprints.

Publisher's note Springer Nature remains neutral with regard to jurisdictional claims in published maps and institutional affiliations.

(c) (i) Open Access This article is licensed under a Creative Commons Attribution 4.0 International License, which permits use, sharing, adaptation, distribution and reproduction in any medium or format, as long as you give appropriate credit to the original author(s) and the source, provide a link to the Creative Commons licence, and indicate if changes were made. The images or other third party material in this article are included in the article's Creative Commons licence, unless indicated otherwise in a credit line to the material. If material is not included in the article's Creative Commons licence and your intended use is not permitted by statutory regulation or exceeds the permitted use, you will need to obtain permission directly from the copyright holder. To view a copy of this licence, visit http://creativecommons.org/licenses/by/4.0/.

(C) The Author(s) 2021 